\title{
MODELLING IN THE CONTEXT OF AN ENVIRONMENTAL MOBILISATION: A GRAPH-BASED APPROACH FOR ASSESSING THE LANDSCAPE ECOLOGICAL IMPACTS OF A HIGHWAY PROJECT
}

\author{
MARC BOURGEOIS ${ }^{1}$, YOHAN SAHRAOUI ${ }^{2,3}$
}

${ }^{1}$ Environnement Ville Société UMR 5600, French National Centre for Scientific Research - University Lyon 3 Jean Moulin, Lyon, France; e-mail: marc.bourgeois@univ-lyon3.fr

${ }^{2}$ Prodig, UMR 8596, French National Centre for Scientific Research, University Paris, 1 Panthéon-Sorbonne, Paris, France ${ }^{3}$ Integrative and Theoretical Ecology Group, LabEx COTE, University of Bordeaux, Bordeaux, France

\begin{abstract}
Bourgeois M., Sahraoui Y.: Modelling in the context of an environmental mobilisation: a graphbased approach for assessing the landscape ecological impacts of a highway project. Ekológia (Bratislava), Vol. 39, No. 1, p. 88-100, 2020.

The construction of highways leads to several environmental and landscape impacts, including the fragmentation of natural habitats for many animal species. Highway projects are therefore generally accompanied by mobilisations from the inhabitants of the areas concerned and environmental associations. This work aims to model the potential impacts of a highway project in France on ecological networks and to study the reception of the results by the opponents of this project. We have adopted a three-step approach. First, a land-cover map of the study area was produced at a fine scale of $10 \mathrm{~m}$ resolution. Second, we developed a multi-species approach by defining fifteen species groups representative of different habitats of our study area. Third, the design of landscape graphs and the resulting calculation of connectivity metrics allowed mapping the impact of the highway on multi-species ecological connectivity. Reflexive feedback from comments on these results by the public during a mobilisation day against the highway project allows assessment of the relevance of such a modelling approach in this context.
\end{abstract}

Key words: cartographic mediation, environmental impact assessment, environmental mobilisation, highway project, landscape graphs, landscape connectivity.

\section{Introduction}

The increase in the world population in recent decades has led to an increasing artificialisation of natural and agricultural areas to support the housing and travel needs of populations. New constructions (e.g., residential buildings, industrial and commercial areas, large sports and leisure facilities) are often accompanied by the construction of new transport networks such as roads or railways. These infrastructures can have significant impacts on ecosystems, both by its physical footprint and its traffic flows (Jaarsma et al., 2013). These constructions favour the spatial process of landscape fragmentation that will affect the habitat patches of animal species by reducing their 
size or increasing their isolation (Fahrig, 2003). This process decreases landscape permeability, making wildlife movements and gene flow more difficult (Forman, Alexander, 1998; Cushman, 2006). The development of landscape ecology in the 1980s led to an increasing number of studies focusing on the ecological impacts of artificialisation on the landscape. The construction of newly built areas can create a barrier effect for species movement (Marull, Mallarach, 2005). However, this kind of fragmentation (sprawl) can be partially mitigated by the possibility of species movement in the interstitial zones of the urban development. The barrier effect depends on the shape and intensity of urbanisation (Alberti, 2005) and is generally intensified in the case of compact and dense cities (Tannier et al., 2016). In terms of transport infrastructure, fragmentation occurs by disconnection and reinforces the barrier effect, often over several tens of kilometres (Forman, Alexander, 1998; Fu et al., 2010; Girardet et al., 2013). Coffin (2007) points out that roads can have significant impacts on all ecosystems: abiotic ecosystem components (hydrological flows, sedimentary flows, water quality, pollutants) and biotic ecosystem components (disruption of animal movements, barrier effects). One of the major effects of roads on landscapes is caused by the direct transformation of natural and agricultural areas into artificial areas (Angelsen, Kaimowitz, 1999). Roads, particularly major infrastructures such as highways, are generally fenced for safety reasons. Traffic volume and speed can make these infrastructures difficult to cross for terrestrial species (Marsh et al., 2008; Holderegger, Di Giulio, 2010; Jaarsma et al., 2013), and can also affect diversity and abundance of other species such as birds (Rashidi et al., 2019). If the roads are crossable, the collision risk is significant for some species and may depend on several factors, such as road traffic, time of day, species behaviour, species size or the abundance of populations in the area (Fahrig, Rytwinski, 2009). This barrier effect of roads can be increased by a change in the behaviour of individuals who can learn to avoid roads in some cases (e.g., Reijnen, Foppen, 2006; Roedenbeck, Voser, 2008). For road networks, fragmentation by cut-off, often over several tens of kilometres, leads to a decrease in habitat quality and a reduction in ecological connectivity (Theobald et al., 1997; Carr et al., 2002). Following the definition proposed by Taylor et al. (1993), ecological connectivity is the degree to which the landscape facilitates or impedes movement among resource patches. Thus, the reduction in ecological connectivity caused by the construction of new transport infrastructure can lead to a significant reduction in biodiversity and ecosystem change on a broader scale (Forman et al., 2003). The preservation of ecological connectivity, and by extension, that of ecological networks, is therefore essential to maintain the movement of animal species between their habitats. The issue of ecological network building and modelling is crucial to create territorial systems of ecological stability (Izakovičová, Świąder, 2017) and to assess the impacts of artificialized areas on ecological connectivity.

Since the 2000s, methods from landscape ecology and graph theory have been used to model the ecological networks of animal species as landscape graphs (Galpern et al., 2011). To assess the functional connectivity of landscapes, the landscape graph approach provides a suitable compromise between the quantity and precision of data required for the analysis and their capacity to represent ecological flows (Calabrese, Fagan, 2004; Urban et al., 2009). This method makes it possible to quantify connectivity by measuring it using spatial metrics (Rayfield et al., 2011). Some studies have focused on a retrospective approach by assessing connectivity losses caused by the construction of major transport infrastructures (e.g., Fu et al., 2010; Clauzel et al., 2013; Girardet et al., 2013). Other studies have used a prospective approach by assessing the potential 
impact of different land-use planning scenarios, such as the construction of a new highway (Vasas et al., 2009) or new residential development areas (Tannier et al., 2012, 2016). These studies have focused on the overall impact of a development or major transport infrastructure on a regional scale (calculation of a global connectivity metric) or habitat patches (calculation of a local metric). However, few studies have attempted to spatialise the potential connectivity of several animal species at any point in the territory. This kind of approach has been explored by Sahraoui et al. (2017) by assessing the retrospective impact of different land use changes. Currently, very few studies use this type of spatial representation to assess the ecological impact of future development projects. On the basis of these statements, our work aims to answer two main questions:

- How do we assess the potential ecological impact of a new highway using landscape graphs for several animal species?

- How can these results be spatially represented to make them explicit and usable for the scientific community and the general public?

To answer these questions, we proceeded in three steps: (1) modelling of ecological networks for a panel of animal species and computation of connectivity metrics in the initial state (before construction of the highway) and in the final state (after construction of the highway), (2) spatial generalisation of connectivity metrics for mapping the potential impacts of the highway on ecological connectivity and (3) reflexive feedback from comments on these results by the general public during a mobilisation day against the highway project.

\section{Material and methods}

\section{Context}

The context of this study is the construction project of a new highway aimed at linking the cities of Lyon and Saint-Étienne in France (Fig. 1). This area is concerned with strong demographic growth, with 60,000 to 65,000 new inhabitants expected by 2030 in the 25 municipalities crossed by the highway (15\% increase in the population). Home-to-work and road transit cannot currently be fully absorbed by the existing railway line and the A47 highway, the fastest way to connect Lyon to Saint-Étienne by road. This new highway project, called 'A45', aims to strengthen exchanges between the two cities and reduce heavy traffic and the many existing traffic jams on the A47 highway.

The planned route of this new highway project is highly controversial for several reasons:

- $\quad$ it is very expensive: for a length of 48 kilometres, four tunnels and eleven viaducts would be necessary;

- it crosses many agricultural areas with high added value (organic farming, short-circuit agricultural production, etc.);

- $\quad$ it threatens several areas of high environmental value, including wetlands;

- $\quad$ it would not provide an efficient local service for people travelling via the A47 between the municipalities crossed by the highway, despite the 3 to 5 interchanges planned. Indeed, the Lyon-Saint-Étienne journey is not always carried out in its entirety by the local population;

- the cost of its toll is too high to allow local inhabitants to use it on a daily basis to travel.

Starting from these issues, mobilisation groups against the highway project (including local farmers, naturalists and residents) organised themselves to fight against this project. In this context, the aim of our work is to raise awareness among the local residents and politicians of the potential ecological impacts of this highway project.

\section{Land-cover map of the study area}

To model the ecological networks of several animal species, the first step in this work was to create an exhaustive land-cover map of the study area. There is currently no exhaustive database in France to determine all land use classes on a small scale. To do this, we used several regional, French and European databases. In each case, the most recent available database was used. The most accurate and widely used database is the $\mathrm{BD}^{\circ} \mathrm{Topo}^{\circ}$, provided by 
the French Geographical Institute (IGN). By compiling these various databases, we created a land-cover map with 26 land-cover classes (Table 1). Figure 1 shows the resulting map with a simplified legend. The land-cover classes provided in vector mode were converted to a raster map with a $10 \mathrm{~m}$ resolution. This high resolution is necessary to take into account fine linear elements such as roads, small rivers or hedges.

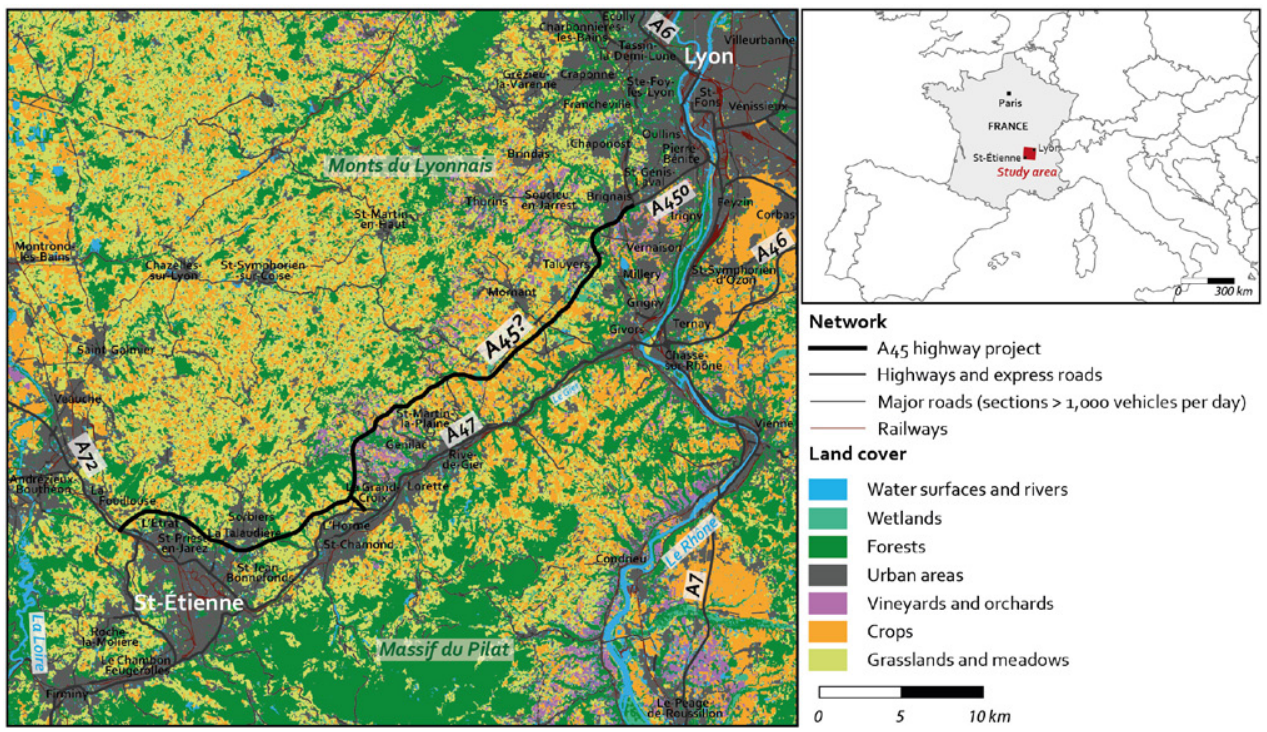

Fig. 1. Land cover map of the study area.

\section{Target species}

Since it seems too simplistic to focus on only one target species (Lindenmayer et al., 2000), we wished to implement a multi-species approach to take into account a representative panel of species in the study area, whether they are ordinary or rare. For this, we reproduced the methodology proposed by Sahraoui et al. (2017) by selecting the species present in the study area, defining their ecological traits and then creating species groups with similar traits. The selection of species present in the study area was made using presence data collected by volunteer naturalists of a wildlife association (LPO Rhône and LPO Loire). These presence data were collected in April 2018 on the websites https://www.faune-rhone.org/ and https://www.faune-loire.org/. In the study area, 426 different species were observed and recorded in the database. Species present in only one municipality in the area were excluded. If a species was present in at least 5 municipalities in the area and well distributed over the territory, it was kept for analysis. We considered that in this case, the species can move and use ecological networks to reach its different potential habitat patches. If a species had been observed only in a few adjacent communes, we excluded it from the study because we considered that given the field observation bias, it could be the same individual. As a result of these filters, 169 species were included. Then, these species were grouped according to three criteria: their taxonomic group, their dispersal distance and their main habitat (identified from the data from the National Institute of Natural Heritage, INPN). The dispersal distances of the species have been identified in the scientific literature, for example, from Smith and Green (2005) for amphibians and reptiles. If the information was not available, especially for birds and mammal, the dispersal distance was estimated from allometric relationships (Sutherland et al., 2000), taking into account the weight of the species, its taxonomic group and its diet as in Sahraoui et al. (2017). The species were then grouped into fifteen groups taking into account their preferred habitat and dispersal distance (Table 2).

Note: ${ }^{\star T h e ~ g r a p h i c a l ~ p a r c e l ~ r e g i s t e r ~(R e g i s t r e ~ P a r c e l l a i r e ~ G r a p h i q u e) ~ i s ~ a ~ d a t a b a s e ~ o f ~ f a r m e r s ’ ~ d e c l a r a t i o n s ~ f o r ~}$ European subsidies. It is therefore very precise when it is filled in but is often incomplete. In this case, we completed 
$\mathrm{T}$ a b l e 1. List of categories, data sources, and processes used to construct the land-cover map of the study area.

\begin{tabular}{|c|c|c|}
\hline Land-cover class & Data sources & Processing performed \\
\hline Buildings & BD Topo IGN (2017) & - \\
\hline Urban areas & European Urban Atlas (2012) & $\begin{array}{l}\text { For urban areas built between } 2012 \text { and } \\
2017 \text {, a } 50 \mathrm{~m} \text { dilation-erosion was made } \\
\text { around artificial areas (buildings, car parks, } \\
\text { industrial areas, etc.) to recreate urban } \\
\text { areas not defined in the European Urban } \\
\text { Atlas }\end{array}$ \\
\hline $\begin{array}{l}\text { Planned route for the } \\
\text { A45 highway }\end{array}$ & Greater Lyon & Digitising the route from a plan \\
\hline Major roads & BD Topo IGN (2017) & - \\
\hline Secondary roads & BD Topo IGN (2017) & - \\
\hline Bridges & BD Topo IGN (2017) & $\begin{array}{l}\text { GIS processing: intersection between roads } \\
\text { and rivers }\end{array}$ \\
\hline High-speed railways & BD Topo IGN (2017) & - \\
\hline Railways & BD Topo IGN (2017) & - \\
\hline Rivers & BD Topo IGN (2017) & - \\
\hline Water surfaces & BD Topo IGN (2017) & - \\
\hline Wetlands & DREAL Auvergne-Rhône-Alpes & \\
\hline Coniferous forests & BD Forêt $(2014)$ & - \\
\hline Mixed forests & BD Forêt $(2014)$ & - \\
\hline Deciduous forests & BD Forêt ${ }^{\circ}(2014)$ & - \\
\hline Groves & BD Topo IGN (2017) & $\begin{array}{l}\text { Selection of vegetation areas between } 500 \\
\text { and } 5,000 \mathrm{~m}^{2}\end{array}$ \\
\hline Hedges & BD Topo IGN (2017) & \multirow{2}{*}{$\begin{array}{l}\text { Extraction of hedges and edges from for- } \\
\text { est areas by morphological spatial pattern } \\
\text { analysis (MSPA) (Vogt et al., 2007) }\end{array}$} \\
\hline Edges & BD Topo IGN (2017) & \\
\hline Crops & $\begin{array}{l}\text { Registre Parcellaire Graphique* (2016), } \\
\text { OSO map (2017) (CESBIO, Toulouse) }\end{array}$ & - \\
\hline $\begin{array}{l}\text { Grassland and mead- } \\
\text { ows }\end{array}$ & $\begin{array}{l}\text { Registre Parcellaire Graphique* (2016), } \\
\text { OSO map (2017) (CESBIO, Toulouse) }\end{array}$ & - \\
\hline Moors & $\begin{array}{l}\text { BD Topo IGN (2017), Registre Parcel- } \\
\text { laire Graphique* }(2016)\end{array}$ & - \\
\hline Lawns & $\begin{array}{l}\text { BD Forêt (2014), OSO map (2017) } \\
\text { (CESBIO, Toulouse) }\end{array}$ & - \\
\hline Orchards & $\begin{array}{l}\text { BD Topo IGN (2017), Registre Par- } \\
\text { cellaire Graphique* (2016), OSO map } \\
\text { (2017) (CESBIO, Toulouse) }\end{array}$ & - \\
\hline Vineyards & $\begin{array}{l}\text { BD Topo IGN (2017), Registre Par- } \\
\text { cellaire Graphique* (2016), OSO map } \\
\text { (2017) (CESBIO, Toulouse) }\end{array}$ & - \\
\hline $\begin{array}{l}\text { Intraurban shrub veg- } \\
\text { etation }\end{array}$ & European Urban Atlas (2012) & - \\
\hline $\begin{array}{l}\text { Intraurban herbaceous } \\
\text { vegetation }\end{array}$ & European Urban Atlas (2012) & - \\
\hline Bare ground & - & $\begin{array}{l}\text { The few pixels remaining after assembling } \\
\text { the different databases were qualified as } \\
\text { 'bare ground. This often corresponds to } \\
\text { interstitial spaces due to various database } \\
\text { sources. }\end{array}$ \\
\hline
\end{tabular}


the information with the OSO map (Inglada et al., 2017) produced by remote sensing by the CESBIO laboratory (Toulouse, France). This database may contain some errors but remains much more accurate than CORINE Land Cover.

\section{Attribution of movement costs}

Each land-cover class is characterised by its capacity to facilitate or impede movements of species between their habitat patches. Following the method proposed in a previous work by Tannier et al. (2016), costs are attributed to the different classes of the landscape matrix according to their resistance to species movements as the following cost units: habitat (1), suitable (10), unfavourable (100), very unfavourable $(1,000)$, and barrier $(10,000)$. These costs were estimated for all 169 species present in each group based on the information available in the literature on individual behaviour. According to the value scales proposed by Gurrutxaga et al. (2010), the cost value of each road section varies between 100 (1,000 vehicles/day) and 1,000 (60,000 vehicles/day).

T a b l e 2. Presentation of the fifteen species groups selected for the study.

\begin{tabular}{|c|c|c|c|c|}
\hline $\begin{array}{l}\text { Code } \\
\text { of the } \\
\text { species } \\
\text { group }\end{array}$ & $\begin{array}{l}\text { Preferential habitat of } \\
\text { the species group }\end{array}$ & $\begin{array}{l}\text { Main taxonomic } \\
\text { group }\end{array}$ & $\begin{array}{l}\text { Dispersal distance } \\
\text { (short : } 0 \text { to } 1 \mathrm{~km} \text {, } \\
\text { medium : } 1 \text { to } 10 \\
\mathrm{~km}, \text { long : } 10 \text { to } \\
100 \mathrm{~km} \text { ) }\end{array}$ & $\begin{array}{l}\text { Examples of species present in } \\
\text { each species group }\end{array}$ \\
\hline 1 & $\begin{array}{l}\text { Aquatic and forest } \\
\text { environment }\end{array}$ & Amphibians & Short & $\begin{array}{l}\text { Lissotriton helveticus, } \\
\text { Pelophylax ridibundus }\end{array}$ \\
\hline 2 & $\begin{array}{l}\text { Aquatic and wetlands } \\
\text { environment }\end{array}$ & $\begin{array}{l}\text { Amphibians, } \\
\text { mammals }\end{array}$ & Medium & $\begin{array}{l}\text { Bombina variegata, } \\
\text { Ichthyosaura alpestris, Lutra lutra }\end{array}$ \\
\hline 3 & Aquatic environments & Birds & Long & $\begin{array}{l}\text { Ardea cinerea, Pandion haliae- } \\
\text { tus, Alcedo atthis }\end{array}$ \\
\hline 4 & Wetlands & Amphibians & Short & $\begin{array}{l}\text { Salamandra salamandra, Rana } \\
\text { dalmatina }\end{array}$ \\
\hline 5 & Wetlands & Reptiles, birds & Medium & Natrix natrix, Anthus pratensis \\
\hline 6 & Wetlands close to forests & Birds & Long & $\begin{array}{l}\text { Scolopax rusticola, Tringa } \\
\text { ochropus }\end{array}$ \\
\hline 7 & $\begin{array}{l}\text { Wetlands close to open } \\
\text { environments }\end{array}$ & Birds & Long & Circus pygargus, Milvus migrans \\
\hline 8 & Forests & Mammals & Medium & $\begin{array}{l}\text { Sciurus vulgaris, Martes martes, } \\
\text { Capreolus capreolus }\end{array}$ \\
\hline 9 & Forests & Birds & Medium & $\begin{array}{l}\text { Dendrocopos minor, Strix aluco, } \\
\text { Periparus ater }\end{array}$ \\
\hline 10 & Forests & Birds & Long & Asio otus, Parus major \\
\hline 11 & Open environments & Insects, reptiles & Short & $\begin{array}{l}\text { Maniola jurtina, Podarcis mu- } \\
\text { ralis }\end{array}$ \\
\hline 12 & Open environments & Birds & Medium & $\begin{array}{l}\text { Ficedula hypoleuca, Phylloscopus } \\
\text { collybita }\end{array}$ \\
\hline 13 & Open environments & Birds & Long & Alauda arvensis, Tyto alba \\
\hline 14 & $\begin{array}{l}\text { Semi-open environ- } \\
\text { ments }\end{array}$ & Birds & Medium & $\begin{array}{l}\text { Emberiza cirlus, Caprimulgus } \\
\text { europaeus }\end{array}$ \\
\hline 15 & $\begin{array}{l}\text { Semi-open environ- } \\
\text { ments }\end{array}$ & Birds & Long & $\begin{array}{l}\text { Phylloscopus bonelli, Hippolais } \\
\text { polyglotta }\end{array}$ \\
\hline
\end{tabular}


These costs are attributed in the case of species that can cross high-traffic roads (e.g., some bird species). As the roads in the study area are often fenced and difficult to cross for terrestrial species, we have reinforced the importance of roads for those species by keeping the same scale of values:

- 1,000 to 5,000 vehicles/day: cost between 1,000 and 3,000;

- $\quad 5,000$ to 10,000 vehicles/day: cost between 3,000 and 7,000;

- $\quad 10,000$ to 20,000 vehicles/day: cost between 7,000 and 8,000;

- 20,000 to 60,000 vehicles/day: cost between 8,000 and 10,000 ;

- $\quad$ More than 60,000 vehicles/day: cost of 10,000.

This empirical cost attribution method may be criticisable by specialists of each species, but it has the advantage of freeing us from collecting long and costly field data. For this reason, this cost attribution system is frequently used in landscape ecology studies (e.g., Verbeylen et al., 2003; Gurrutxaga et al., 2011; Clauzel et al., 2013; Bourgeois et al., 2018). The final cost assigned to each land-cover class for one species group is the average of the costs assigned for this land-cover class for all the species of this group.

\section{Construction of graphs}

A landscape graph is a set of nodes and links used to model the ecological networks of each species group; nodes represent habitat patches, and links represent possible movements between these patches. Patches are extracted from land-cover classes. For example, for a forest species, habitat patches are land-cover pixels of the 'forest' type. For each species group, we did not define a minimum area of habitat patches. The links between habitat patches are represented by the average dispersal distance of each species group and converted into cost distance. The links represent the least-cost paths between each habitat patch and are thresholded by the dispersal distance of the species group studied. Thirty landscape graphs were generated for this work: fifteen in the initial state (one for each species group) and fifteen in the final state, after adding the A45 highway to the land-cover map. Landscape graphs were computed with Graphab 2.4 software (Foltête et al., 2012).

\section{Computation of connectivity metrics}

The construction of landscape graphs allows the calculation of connectivity metrics to quantify ecological connectivity for the entire graph (global metric) or for each habitat spot (local metric). The global metric used here is the equivalent connectivity (EC) (Saura et al., 2011), characterising the connectivity potential across the entire ecological network and measured as follows:

$$
E C=\sqrt{\sum_{i=1}^{n} \sum_{j=1}^{n} a_{i} a_{j} e^{-\alpha d_{i j}}}
$$

where $n$ is the total number of patches, $a_{i}$ and $a_{j}$ are the areas of patches $i$ and $j$, and is the maximum probability of potential paths between $i$ and $j$. was calculated with an exponential function such that:

$$
p_{i j}=e^{-\alpha d_{i j}}
$$

where $d_{i j}$ is the least-cost distance between $i$ and $j$, and $\alpha(0<\alpha<1)$ expresses the intensity of decreasing probability of dispersion resulting from the exponential function.

To quantify the loss of connectivity at the scale of each habitat patch, we chose the local metric interaction flux (IF) (Foltête et al., 2014; Sahraoui et al., 2017), which is the local contribution of each patch to the global EC metric. For a given patch, $i$, is given by:

$$
I F_{i}=\sum_{j=1}^{n} a_{i}^{\beta} a_{j}^{\beta} e^{-\alpha d_{i j}}
$$

where $n$ is the total number of patches, $a_{i}$ and $a_{j}$ are the areas of patches $i$ and $j$, and is the maximum probability of potential paths between $i$ and $j$. 
Unlike the global EC metric, the computation of this metric allows us to spatialise connectivity for each habitat patch. The main disadvantage is that connectivity values are only computed for habitat patches, making comparisons difficult for species groups with patches of different habitats (e.g., forest habitats and wetland habitats).

To do this, we reproduced the approach proposed by Sahraoui et al. (2017) to evaluate the potential accessibility of any point (i.e., pixel) of the overall study area on the landscape graph of several species groups. In our case and for a given group, the patch-level connectivity value $(I F)$ was used. This spatial generalisation relies on the assumption that individuals may be found outside habitat patches, although with a lower probability than being found within their habitat patches (Hirzel, Le Lay, 2008). Based on this assumption, (1) a given point located outside the patches was considered potentially connected to the habitat network by inheriting the connectivity levels from the surrounding patches, and (2) the influence of a patch towards a point should decrease with distance, so that the farther the point from the ecological network, the lower its potential connectivity. The weighting function designed to represent this distance effect is identical to that used to compute the $E C$ index, that is, the negative exponential function where is the weight of a patch with respect to a point located at a least-cost distance $d$. For a given point, connectivity levels from several patches were attributed by summing the weighted values of $I F$ as follows by taking into account least-cost distances:

$$
g I F(i)_{i}=\sum_{j=1}^{n} I F_{(j)} \times \omega_{i j}
$$

where is the generalised value of $I F$ for point $i$, and is the weighting of patch $j$ for point $i$.

As a result, we obtained for each species group a $10 \mathrm{~m}$ resolution map in the initial state and in the final state (after adding the highway), on which each pixel took on a value corresponding to its potential of connectivity to the overall network. For each of the species groups, a new map was created, resulting from the calculation of the rate of change between the initial and final state for each pixel of the map.

\section{Results}

\section{Global connectivity assessment}

The average estimated change in global connectivity for each species group is $-2.53 \%$ in the $E C$ metric. However, this average is difficult to interpret because the ecological connectivity losses are very different between each species group (see Fig. 2).

We did not observe a direct link between the main habitat class and the observed impacts, suggesting a stronger role of movement behaviour. For example, the connectivity of species group $\mathrm{n}^{\circ} 5$ is significantly affected by the highway project since the planned route cuts through many wetlands that support the habitat and movement of the species concerned. Conversely, the impact of the highway is almost zero for species group $n^{\circ} 1$, whose habitats and potential movement areas are very distant from the route.

\section{Local connectivity assessment}

With spatial generalisation of local connectivity metrics, we designed fifteen maps spatialising the impact of the highway on functional connectivity for each species group studied, for example, for species group $n^{\circ} 5$ and $n^{\circ} 12$, whose main habitats and global impacts are differentiated (Fig. 3 ). For both groups, our results showed a strong impact in the area between the existing A47 highway and the future A45 highway. This result can be explained by the fact that the A47 highway, built in parallel with industrial areas and a river, is already a strong barrier to the movement of species, 


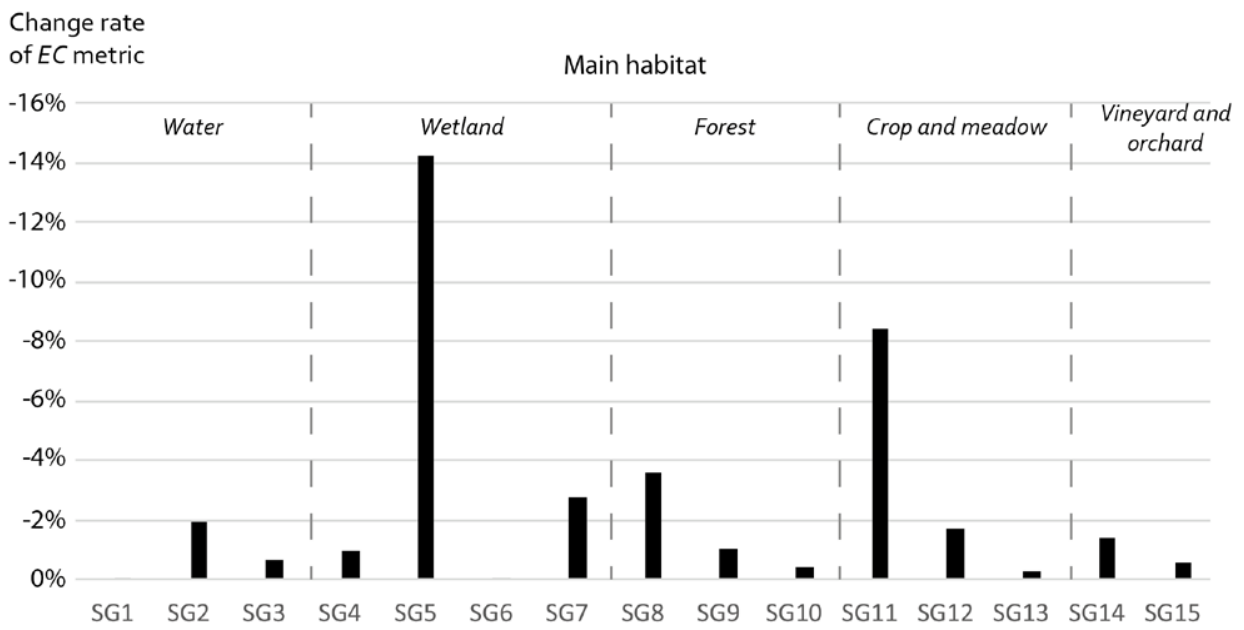

Fig. 2. Assessment of loss of connectivity for the entire study area. The change rate of the EC index is computed with an assessment of connectivity at the initial state (before construction of the highway) and the final state (after construction of the highway). SG means 'species group', and the number is the code of each species group detailed in Table 2.

including flying species. The construction of the highway would tend to create a new barrier in the north and drastically reduce ecological connectivity in the area between the two highways. However, the A45 project also affects connectivity away from the highway path. In the case of the group $\mathrm{n}^{\circ} 5$, the impact values remaining high in the north of the A45 project, gradually decreasing with distance. For the group $n^{\circ} 12$, the impacts are however stronger in the southern part, with isolated very high impacts in the hearth of the Massif $d u$ Pilat.

These mapping results were then formatted and printed on A0 posters to be presented to the general public during a day of mobilisation against the A45 highway in La Talaudière (a small town near Saint-Étienne). This event, which took place on 22 September 2018, brought together nearly 3,000 people (general public and local elected officials), mainly against the highway project. The presentation of the mapping results in workshops during the day (see Fig. 4), accompanied by explanations of the concept of ecological connectivity, opened the debate on the potential ecological impacts of the highway among approximately one hundred people who participated in the workshops.

\section{Discussion and conclusion}

This work was made possible by an effective reuse of methods presented in other works to assess the ecological impact of land use planning projects or land-cover changes (e.g., Girardet et al., 2013; Mimet et al., 2016; Tannier et al., 2016; Sahraoui et al., 2017). The construction of a finescale land use map and the implementation of a multi-species approach have enabled the modelling of landscape graphs. Based on these graphs, the calculation of global and local connectivity metrics allowed us to assess the potential impacts of the A45 highway project on a set of species representative of the different natural environments crossed by this project. Although global con- 

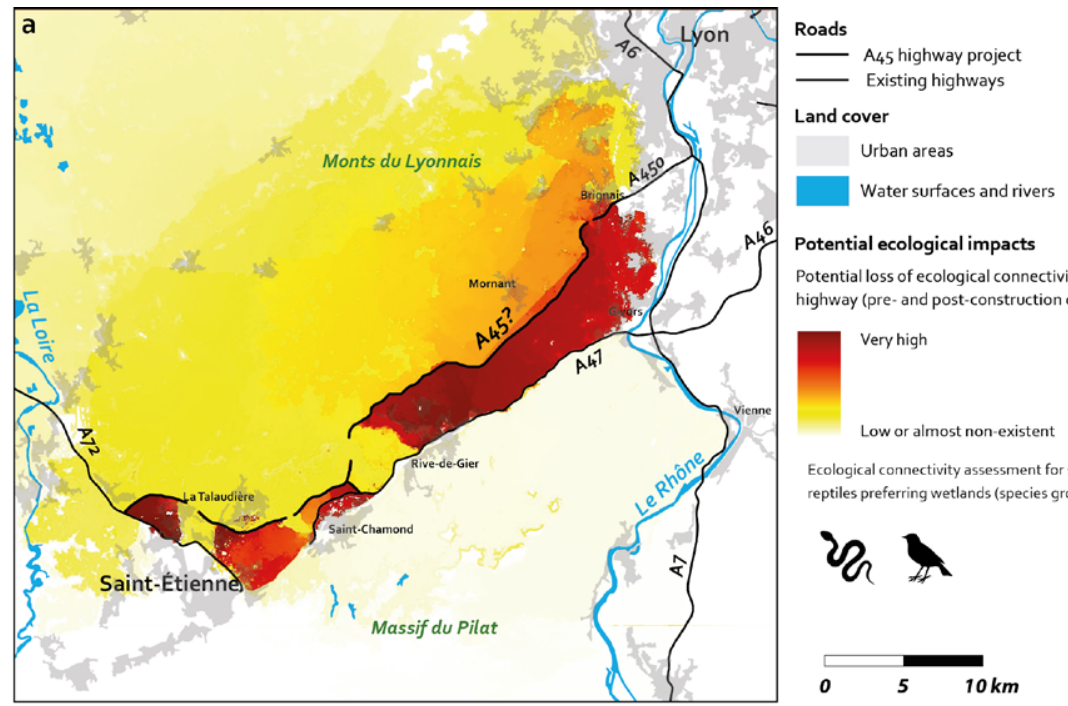

Roads

- A45 highway project Existing highways

Land cover

Urban areas
Water surfaces and rivers

Potential ecological impacts

Potential loss of ecological connectivity caused by the $\mathrm{A}_{45}$ highway (pre-and post-construction differential)

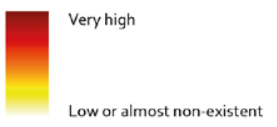

Ecological connectivity assessment for several birds and reptiles preferring wetlands (species group $n^{\circ} 5$ )

\section{iq}
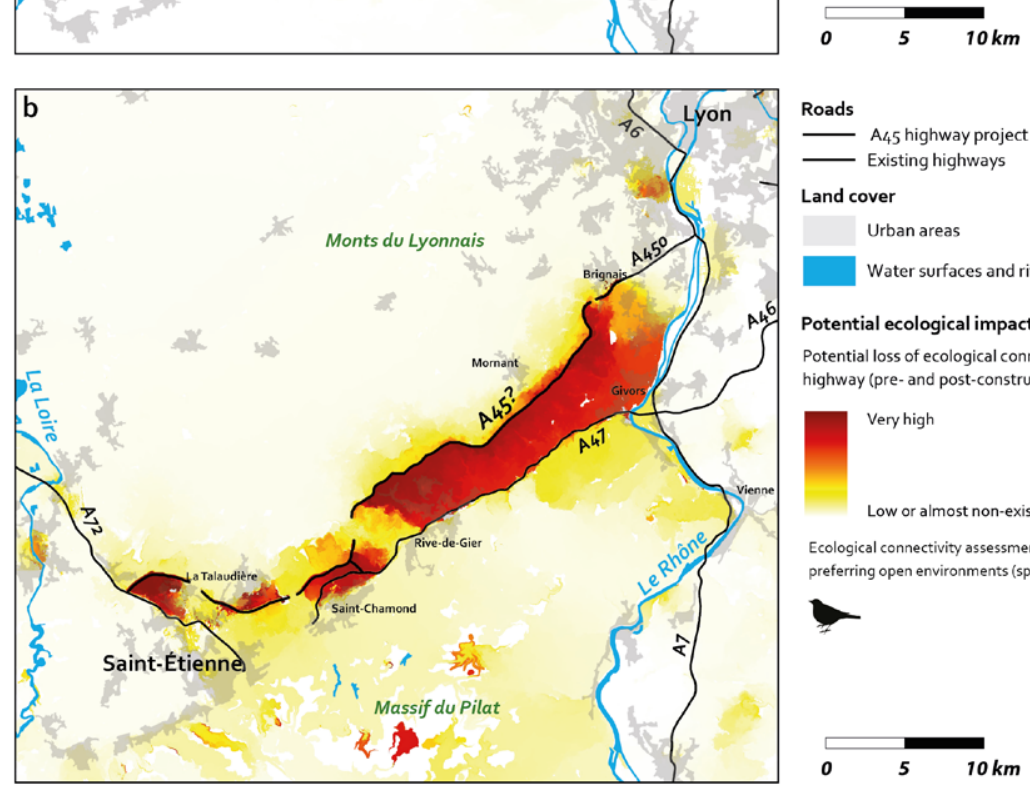

Roads

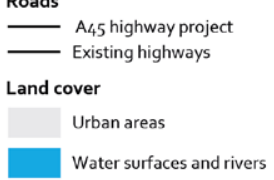

Potential ecological impacts

Potential loss of ecological connectivity caused by the $A_{45}$ highway (pre- and post-construction differential)

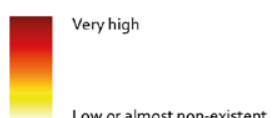

Ecological connectivity assessment for several birds preferring open environments (species group $n^{\circ} 12$ )

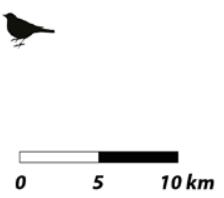

Computations with the Graphab software: Marc Bourqeois (UMR EVS, University Lyon 3) and Gilles Vuidel (UMR ThéMA, University of Bourqogne-Franche-Comté)

Fig. 3. Map of the potential impacts of the A45 highway on functional connectivity for species group $\mathrm{n}^{\circ} 5$ (a) and species group $n^{\circ} 12(b)$.

nectivity metrics (i.e., for an entire study area) have been useful in comparing the sensitivity of species groups to the highway project, they only provide an overview of the impacts. The main limitation of these results lies in the lack of information on the location of the impacts. The spatial generalisation of local connectivity metrics allowed us to overcome this limitation. From this, several maps of the impacts of the highway project were produced and presented during a day of 


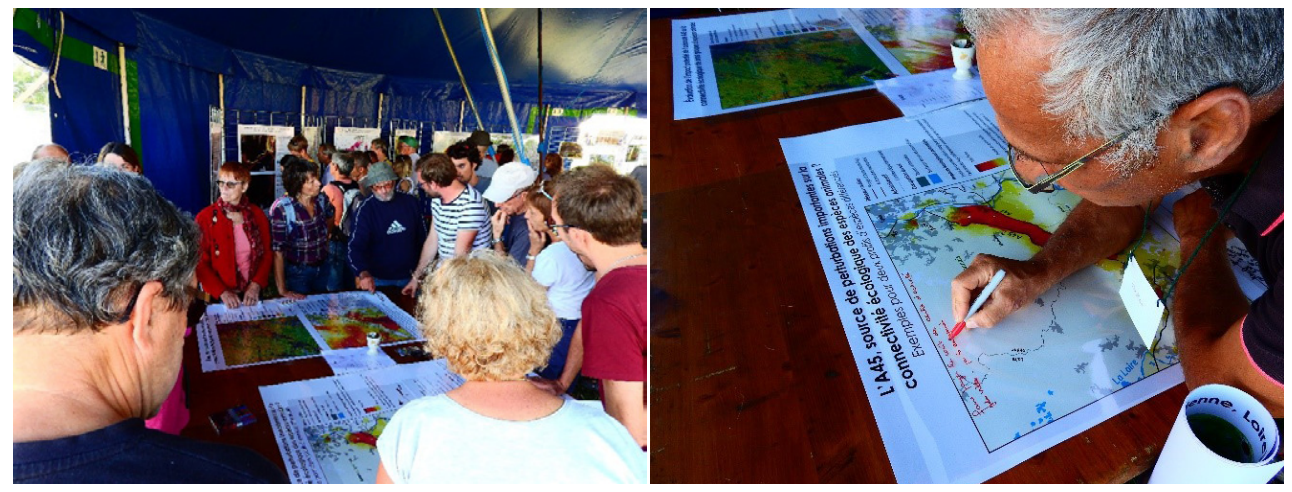

Fig. 4. Workshop and debates around connectivity maps during a mobilisation day at La Talaudière (22 September 2018).

mobilisation against the project. These discussions made it possible to evaluate the reception by a neophyte public of geographical information produced as part of a research process.

First, workshop participants were often surprised by the spatial extent of the impacts of the highway project. Indeed, naturalist collectives are often used to present the impacts of the highway in the immediate environment of the route, while our maps (e.g., Fig. 3b) show impacts far from the infrastructure (up to $15-20 \mathrm{~km}$ in some cases). For example, we can observe a significant loss of connectivity in the south of the area (Pilat massif) at a significant distance from the route. However, these remote impacts were difficult for some people to understand, but they were useful in highlighting and explaining the concept of ecological networks. We also presented a map to show the highest connectivity loss for each of the species groups. This map, resulting from the combination of the fifteen maps produced, showed results that were more difficult to understand for the public and required more explanations. An a priori scientific mediation, therefore, seems necessary to support the public in the interpretation of the results. Other maps, more understandable to the public, were also presented during the day. Some of them showed the expected changes in urbanisation in the municipalities near the route (spatialization of the future areas to be urbanised and the expected variation in the population of each municipality in the study area). These maps are not directly related to the ecological impacts of the highway project but have made people aware of the need to find new medium-term mobility solutions instead of this new highway.

One of the major limitations of this study is that many data processing operations were necessary to prepare these results. To produce these maps in a limited time, we had to make many choices, many of which can be criticised from a scientific point of view (representation of land use classes, choice of species, allocation of costs, for example). However, these choices were necessary to model the ecological connectivity over a study area of several tens of square kilometres. Despite our explanations during the workshops, the understanding and interpretation of the results can be biased by the 'black box' effect of the processes. To overcome this problem, it would be appropriate to involve participants at different stages of the modelling process from a participatory modelling perspective.

Finally, people were mainly satisfied to observe that the highway project could have a significant impact on ecological connectivity on a large scale, legitimising their fight against the highway 
route using nature conservation arguments. While spatial modelling tools are generally used in a decision-making context with political decision-makers and planners, this work opens the door to the use of spatial modelling in the context of citizen mobilisation.

\section{Acknowledgements}

This work was conducted as part of the ECOMOLY research project funded by the University of Lyon 3 Jean Moulin. We thank Judicaëlle Dietrich, Gérémine Girard and Marie Detemple for their participation in facilitating the participative workshops, Ismail Sanchez-Penas for the construction of the land cover map, and Gilles Vuidel for helping compute ecological networks, as well as all workshop participants.

\section{References}

Alberti, M. (2005). The effects of urban patterns on ecosystem function. International Regional Science Review, 28, 168-192. DOI: 10.1177/0160017605275160.

Angelsen, A. \& Kaimowitz D. (1999). Rethinking the causes of deforestation : Lessons from economic models. World Bank Research Observer, 14, 73-98. DOI: 10.1093/wbro/14.1.73.

Bourgeois, M., Cossart, É. \& Fressard M. (2018). Mesurer et spatialiser la connectivité pour modéliser les changements des systèmes environnementaux. Approches comparées en écologie du paysage et en géomorphologie. Géomorphologie Relief Processus Environnement, 23, 289-308. DOI: 10.4000/geomorphologie.11895.

Calabrese, J.M. \& Fagan W.F. (2004). A comparison-shopper's guide to connectivity metrics. Frontier Ecology Environment, 2, 529-536. DOI: $10.2307 / 3868383$.

Carr, L.W., Fahrig, L. \& Pope S.E. (2002). Impacts of landscape transformation by roads. In K.J. Gutzwiller (Ed.), Applying landscape ecology in biological conservation (pp. 225-243). New-York: Springer-Verlaag.

Clauzel, C., Girardet, X. \& Foltête J.-C. (2013). Impact assessment of a high-speed railway line on species distribution: application to the European tree frog (Hyla arborea) in Franche-Comté. J. Environ. Manag., 127, $125-134$. DOI: 10.1016/j.jenvman.2013.04.018.

Coffin, A.W. (2007). From roadkill to road ecology : A review of the ecological effects of roads. Journal of Transport Geography, 15, 396-406. DOI: 10.1016/j.jtrangeo.2006.11.006.

Cushman, S.A. (2006). Effects of habitat loss and fragmentation on amphibians: A review and prospectus. Biol. Conserv., 128, 231-240. DOI: 10.1016/j.biocon.2005.09.031.

Fahrig, L. (2003). Effects of habitat fragmentation on biodiversity. Annu. Rev. Ecol. Evol. Syst., 34, 487-515. DOI: 10.1146/annurev.ecolsys.34.011802.132419.

Fahrig, L. \& Rytwinski T. (2009). Effects of roads and traffic on wildlife populations and landscape function effects of roads on animal abundance: an empirical review and synthesis. Ecol. Soc., 14, 21. DOI: 10.5751/es-02815140121.

Foltête, J.-C., Clauzel, C. \& Vuidel G. (2012). A software tool dedicated to the modelling of landscape networks. Environmental Modelling and Software, 38, 316-327. DOI: 10.1016/j.envsoft.2012.07.002.

Foltête, J.-C., Girardet, X. \& Clauzel C. (2014). A methodological framework for the use of landscape graphs in landuse planning. Landsc. Urban Plann., 124, 140-150. DOI: 10.1016/j.landurbplan.2013.12.012.

Forman, R.T.T. \& Alexander L.E. (1998). Roads and their major ecological effects. Annu. Rev. Ecol. Syst., 29, 207231. DOI: 10.1146/annurev.ecolsys.29.1.207.

Forman, R.T.T., Sperling, D., Bissonette, J.A., Clevenger, A.P., Cutshall, C.D., Dale, V.H., Fahrig, L., France, R., Goldman, C.R., Heanue, K., Jones, J.A., Swanson, F.J., Turrentine, T. \& Winter T.C. (2003). Road ecology: Science and solutions. Washington: Island Press.

Fu, W., Liu, S., Degloria, S.D., Dong, S. \& Beazley R. (2010). Characterizing the 'fragmentation-barrier' effect of road networks on landscape connectivity: A case study in Xishuangbanna, Southwest China. Landsc. Urban Plann., 95, 122-129. DOI: 10.1016/j.landurbplan.2009.12.009.

Galpern, P., Manseau, M. \& Fall A. (2011). Patch-based graphs of landscape connectivity: A guide to construction, analysis and application for conservation. Biol. Conserv., 144, 44-55. DOI: 10.1016/j.biocon.2010.09.002.

Girardet, X., Foltête, J.-C. \& Clauzel C. (2013). Designing a graph-based approach to landscape ecological assessment of linear infrastructures. Environmental Impact Assessment Review, 42, 10-17. DOI: 10.1016/j.eiar.2013.03.004. 
Gurrutxaga, M., Lozano, P.J. \& Del Barrio G. (2010). Assessing highway permeability for the restoration of landscape connectivity between protected areas in the Basque Country, Northern Spain. Landscape Research, 35, 529-550. DOI: 10.1080/01426397.2010.504915.

Gurrutxaga, M., Rubio, L. \& Saura S. (2011). Key connectors in protected forest area networks and the impact of highways: A transnational case study from the Cantabrian Range to the Western Alps (SW Europe). Landsc. Urban Plann., 101, 310-320. DOI: 10.1016/j.landurbplan.2011.02.036.

Hirzel, A.H. \& Le Lay G. (2008). Habitat suitability modelling and niche theory. Journal of Applied Ecology, 45, 1372-1381. DOI: 10.1111/j.1365-2664.2008.01524.x.

Holderegger, R. \& Di Giulio M. (2010). The genetic effects of roads: A review of empirical evidence. Basic and Applied Ecology, 11, 522-531. DOI: 10.1016/j.baae.2010.06.006.

Inglada, J., Vincent, A., Arias, M., Tardy, B., Morin, D. \& Rodes I. (2017). Operational high resolution land cover map production at the country scale using satellite image time series. Remote Sensing, 9, 95. DOI: 10.3390/rs9010095.

Izakovičová, Z. \& Świąder M. (2017). Building ecological networks in Slovakia and Poland. Ekológia (Bratislava), 36(4), 302-322. DOI: 10.1515/eko-2017-0025.

Jaarsma, C.F., van Langeve, F. \& Beunen R. (2013). Landscape ecology and Rural roads: traffic calming for improving both landscape and wildlife? Ekológia (Bratislava), 32(4), 352-360. DOI: 10.2478/eko-2013-0032.

Lindenmayer, D.B., Margules, C.R. \& Botkin D.B. (2000). Indicators of biodiversity for ecologically sustainable forest management. Conserv. Biol., 14, 941-950. DOI: 10.1046/j.1523-1739.2000.98533.x.

Marsh, D.M., Page, R.B., Hanlon, T.J., Corritone, R., Little, E.C., Seifert, D.E. \& Cabe P.R. (2008). Effects of roads on patterns of genetic differentiation in red-backed salamanders, Plethodon cinereus. Conservation Genetics, 9, 603-613. DOI: $10.1007 /$ s10592-007-9377-0.

Marull, J. \& Mallarach J.M. (2005). A GIS methodology for assessing ecological connectivity: application to the Barcelona Metropolitan Area. Landsc. Urban Plann., 71, 243-262. DOI: 10.1016/j.landurbplan.2004.03.007.

Mimet, A., Clauzel, C. \& Foltête J.-C. (2016). Locating wildlife crossings for multispecies connectivity across linear infrastructures. Landsc. Ecol., 31, 1955-1973. DOI: 10.1007/s10980-016-0373-y.

Rashidi, M., Chamani, A. \& Moshtaghi M. (2019). The influence of transport infrastructure development on bird diversity and abundance. Ekológia (Bratislava), 38(2), 178-188. DOI: 10.2478/eko-2019-0014.

Rayfield, B., Fortin, M.-J. \& Fall A. (2011). Connectivity for conservation: a framework to classify network measures. Ecology, 92, 847-858. DOI: 10.1890/09-2190.1.

Reijnen, R. \& Foppen R.P.B. (2006). Impact of road traffic on breeding bird populations. In J. Davenport \& J.L. Davenport (Eds.), The ecology of transportation: Managing mobility for the environment (pp. 255-274). Dordrecht: Springer.

Roedenbeck, I.A. \& Voser P. (2008). Effects of roads on spatial distribution, abundance and mortality of brown hare (Lepus europaeus) in Switzerland. European Journal of Wildlife Research, 54, 425-437. DOI: 10.1007/s10344-007-0166-3.

Sahraoui, Y., Foltête, J.-C. \& Clauzel C. (2017). A multi-species approach for assessing the impact of land-cover changes on landscape connectivity. Landsc. Ecol., 32, 1819-1835. DOI: 10.1007/s10980-017-0551-6.

Saura, S., Estreguil, C., Mouton, C. \& Rodriguez-Freire M. (2011). Network analysis to assess landscape connectivity trends: Application to European forests (1990-2000). Ecol. Indic., 11, 407-416. DOI: 10.1016/j.ecolind.2010.06.011.

Tannier, C., Foltête, J.-C. \& Girardet X. (2012). Assessing the capacity of different urban forms to preserve the connectivity of ecological habitats. Landsc. Urban Plann., 105, 128-139. DOI: 10.1016/j.landurbplan.2011.12.008.

Tannier, C., Bourgeois, M., Houot, H. \& Foltête J.-C. (2016). Impact of urban developments on the functional connectivity of forested habitats: A joint contribution of advanced urban models and landscape graphs. Land Use Policy, 52, 76-91. DOI: 10.1016/j.landusepol.2015.12.002.

Taylor, P.D., Fahrig, L., Henein, K. \& Merriam G. (1993). Connectivity is a vital element of landscape structure. Oikos, 68, 571-573. DOI: $10.2307 / 3544927$.

Theobald, D.M., Miller, J.R. \& Hobbs N.T. (1997). Estimating the cumulative effects of development on wildlife habitat. Landsc. Urban Plann., 39, 25-36. DOI: 10.1016/S0169-2046(97)00041-8.

Urban, D.L., Minor, E.S., Treml, E.A. \& Schick R.S. (2009). Graph models of habitat mosaics. Ecol. Lett., 12, 260-273. DOI: 10.1111/j.1461-0248.2008.01271.x.

Vasas, V., Magura, T., Jordán, F. \& Tóthmérész B. (2009). Graph theory in action: evaluating planned highway tracks based on connectivity measures. Landsc. Ecol., 24, 581-586. DOI: 10.1007/s10980-009-9346-8.

Verbeylen, G., De Bruyn, L., Adriaensen, F. \& Matthysen E. (2003). Does matrix resistance influence Red squirrel (Sciurus vulgaris L. 1758) distribution in an urban landscape? Landsc. Ecol., 18, 791-805. DOI: 10.1023/B: LAND.0000014492.50765.05.

Vogt, P., Riitters, K.H., Estreguil, C., Kozak, J., Wade, T.G. \& Wickham J.D. (2007). Mapping spatial patterns with morphological image processing. Landsc. Ecol., 22, 171-177. DOI: 10.1007/s10980-006-9013-2. 